\title{
El genoma bovino, métodos y resultados de su análisis
}

\section{The bovine genome, methods and results of its analysis}

\author{
Janeth Ortega T, ${ }^{1}$ M.Sc, Luís García P, ${ }^{2}$ Ph.D.
}

\begin{abstract}
${ }^{1}$ Universidad Nacional de Colombia. Departamento de Biología. Facultad de Ciencias. Sede Bogotá. ${ }^{2}$ Universidad Nacional de Colombia. Facultad de Medicina Veterinaria y Zootecnia. Bogotá. Correspondencia: yanethortega2001@yahoo.com
\end{abstract}

Recibido: Junio de 2009; Aceptado: Febrero de 2010.

\section{RESUMEN}

El conocimiento del genoma de especies domésticas ha permitido la selección de características importantes para la producción y la aplicación de técnicas moleculares en mejoramiento genético. El objetivo de esta revisión fue presentar la metodología que se utilizó para el secuenciamiento del genoma bovino, describir la estructura molecular y presentar los principales hallazgos de este proyecto. Se describen las principales herramientas y metodologías utilizadas para el secuenciamiento del genoma, la naturaleza molecular y las perspectivas que de este conocimiento surgen para el desarrollo de la medicina veterinaria y la producción animal. Se resalta la importancia del uso de estas estrategias de estudio para comparaciones evolutivas y la búsqueda de genes bovinos para características importantes de producción y loci de características cuantitativas (QTLs). Se incluyen los genes anotados a la fecha, la sintenia entre especies, al igual que los cromosomas bovinos mejor descritos. Finalmente se resumen las perspectivas de utilización de este conocimiento en el campo de la producción y conocimiento del genoma bovino, las repercusiones en el estudio comparativo entre razas y el mejoramiento genético de las especies.

Palabras clave: Genomas, bovino, secuenciación de ADN, anotación de genes, secuencias repetitivas, evolución. (Fuente: $\mathrm{MeSH}$ ) 


\section{ABSTRACT}

The knowledge of the genome in domestic species has allowed the selection of important characteristics for production and the development of molecular techniques used for animal genetic improvement. The objective of this review is to present the methodology used for sequencing the bovine genome, describe some findings of the genome structure and to introduce the main discoveries of the Bovine Genome Project. The main tools and methodologies used for sequencing the genome are described. Also, the main perspectives that from this knowledge arise for the development of veterinary medicine and animal production are discussed. Emphasis is put on the importance of the use of these strategies of study, the evolutionary comparisons and the search of bovine genes for important characteristics in production and quantitative trait loci. Annotated genes up to date, the synteny of genes between species and the best-described chromosomes are included. Finally a summary of the main perspectives from using this knowledge in the field of production, the knowledge of the bovine genome, the consequences in the comparative study among species and the genetic improvement of species is presented.

Key words: Genome, bovine, sequence analysis, DNA, gene annotation, repetitive sequence, evolution. (Sources: MeSH)

\section{INTRODUCCIÓN}

Las especies bovinas constituyen un grupo muy importante de animales, no sólo por su posibilidad de explotación y aporte en la economía de muchos países, sino por ser de las primeras especies domesticadas por el hombre, hecho que le ha permitido acompañarlo en su evolución y viajes a lo largo de diferentes rutas migratorias a través de la historia. El ganado bovino representa así junto con los cerdos, perros y gatos una clase de mamíferos placentados que han coevolucionado con los humanos y su estudio permite no sólo ampliar el conocimiento de estas especies, sino brindar huellas importantes sobre la evolución e historia natural de las mismas.

El avance en los estudios genéticos de las especies animales ha contribuido ampliamente a entender muchos campos de la medicina humana. En la endocrinología, por ejemplo, estudios clásicos en animales permitieron entender la regulación de las hormonas pituitarias y reproductivas. La composición de la insulina fue primero descrita a partir del estudio de la insulina bovina (1), la warfarina fue desarrollada gracias a la identificación de una patología en la sangre de los bovinos (2) (enfermedad de Sweet Clover), las hormonas tiroidea y paratiroidea fueron identificadas en extractos de suero bovino (3), al igual que el efecto de la hormona luteinizante (4). Estudios con extractos pituitarios bovinos inyectados a ratas permitieron identificar y conocer el efecto de la hormona de crecimiento $(5,6)$.

Se debe resaltar el aporte de técnicas de biotecnología reproductiva desarrolladas inicialmente en bovinos tales como: técnicas de superovulación, cultivo de oocitos, fertilización in vitro, maduración y congelación de embriones, las cuales se implementaron posteriormente en humanos. Además la investigación en semen de bovinos ha permitido el desarrollo de técnicas aplicadas a humanos y otras especies (7).

En bovinos existe una importante variabilidad genética, representada por más de 783 razas (8) distribuidas en todo el mundo, en las cuales una amplia diversidad de fenotipos es debida a características genéticas, lo que permite la posibilidad de realizar mejoramiento con el fin de obtener rendimientos superiores en características específicas altamente deseables para la producción, tales como 
incremento en el crecimiento, composición de los productos (e.g. leche, carne, etc.), fertilidad, capacidad de adaptación a múltiples ambientes y resistencia a diferentes patologías, entre otras (8).

Distintos avances tecnológicos en la reproducción, el conocimiento del genoma y la aplicación de métodos estadísticos para maximizar la producción, aumentan la posibilidad de ganancia en países cuya economía es soportada por diversos tipos de explotación ganadera, lo que hace que rápidamente se invierta en tecnología, incrementando el conocimiento y desarrollo en esta área.

Con el fin de obtener información amplia y consolidada del genoma bovino, en el año 2003 surge la iniciativa para secuenciar, ensamblar y anotar el genoma completo. Esta iniciativa estuvo apoyada por la importancia que los bovinos tienen para estudios de evolución de las especies, por la búsqueda continua de QTLs y por la posibilidad de extrapolar la medicina humana con la medicina veterinaria. Para tal fin se creó el Consorcio Internacional, liderado por el Baylor College (Houston, Texas, USA), con el apoyo de varias entidades y gobiernos con un presupuesto total de 53 millones de dólares cuyo objetivo principal fue secuenciar y ensamblar un prototipo del genoma bovino, obtener información detallada acerca de los genes bovinos, generar una base de datos con información de polimorfismos de nucleótidos simples (SNPs).

A partir de esa fecha, el consorcio puso a disposición los resultados obtenidos en internet a medida que estos se fueron generando. Este proyecto mostró que el genoma bovino puede contener como mínimo 22,000 genes, además de una serie de segmentos duplicados y elementos repetitivos. Se observó que existe una variación inter especie con respecto a los genes asociados con lactancia y respuesta inmunológica (9). El objetivo de esta revisión fue presentar la metodología que se utilizó para el secuenciamiento del genoma bovino, describir la estructura molecular y presentar los principales hallazgos del proyecto.

\section{Metodología de análisis de los genomas.}

Diferentes técnicas de biología molecular han permitido el conocimiento detallado de los genomas. El desarrollo y aplicación de técnicas de mapeo físico, genético y comparativo, permiten la posibilidad de asignación física específica de los genes dentro de un cromosoma, establecen la sintenia entre marcadores y obtienen de manera conjunta, información tanto de genes como de marcadores (10). El avance en el conocimiento de la química de los ácidos nucleicos, la automatización de los procesos de laboratorio y la biología computacional, han contribuido al conocimiento de la organización y variabilidad genética de las especies, a tal punto, que en la actualidad se dispone de pruebas de laboratorio que permiten obtener información rápida y confiable de caracteres genéticos de importancia económica en especies de gran valor productivo. Algunos ejemplos en bovinos incluyen la detección de genes como los de la tiroglobulina, la calpastatina y la miostatina, implicados en características como el marmóreo, la terneza de la carne y la doble musculatura respectivamente (11).

\section{Mapas físicos, genéticos y de desequilibrio de ligamiento}

Los mapas físicos. Permiten la localización exacta de genes dentro de los cromosomas. Estos mapas son construidos utilizando técnicas tales como híbridos somáticos, híbridos por radiación $(\mathrm{RH})$ e hibridación in situ fluorescente (FISH). Con los híbridos somáticos se retienen cromosomas específicos, luego de la fusión de dos células de diferente origen, delimitando la búsqueda de genes a cromosomas particulares. Mientras que con los híbridos por radiación, se retienen fragmentos de cromosomas que han sido obtenidos después de irradiar las células con diferentes dosis de radiación, delimitando aún más la búsqueda de genes a fragmentos más pequeños de los cromosomas (12). Las especies animales más comúnmente utilizadas para tal fin son: hámster, ratón, humano y líneas 
celulares procedentes de estas especies (12). Mediante la Hibridación in situ fluorescente, se localizan genes dentro de los cromosomas gracias a la utilización de sondas específicas, frecuentemente generadas a partir de RNAs mensajeros marcadas con agentes fluorescentes (13).

Mapas genéticos o de ligamiento. Se obtienen a partir de la información generada de estudios de pedigrí en donde se realizan observaciones de características asociadas con marcadores específicos. A través de las generaciones, estos marcadores cosegregan (se segregan conjuntamente el marcador y el gen responsable para un fenotipo determinado) con una característica específica, pudiéndose reconocer en la progenie los porcentajes de los descendientes que portan el gen responsable del fenotipo junto con el marcador y el porcentaje de los recombinantes. Con esta metodología se han detectado muchas patologías genéticas relativamente raras. Dichos porcentajes permiten establecer la distancia genética entre diferentes marcadores, la cual es medida en cM (centimorgan). Esta medida no necesariamente corresponde a una distancia física exacta en pares de bases (14).

Mapas de desequilibrio de ligamiento. Desequilibrio de ligamiento significa una asociación no al azar de alelos de 2 o más loci, de tal manera, que los mapas de desequilibrio de ligamiento brindan información sobre estas asociaciones en el genoma completo o en bloques del mismo. La detección de desequilibrio de ligamiento es de importancia en biología evolutiva y genética debido a que permite obtener información acerca de eventos pasados. Cuando se estudia el desequilibrio de ligamiento en el genoma completo, se puede obtener información sobre la historia natural de las poblaciones, los sistemas de apareamiento y el patrón de subdivisiones geográficas, mientras que estudiando bloques particulares del genoma se obtiene información sobre posibles efectos de selección natural, eventos de conversión génica, mutación y otras fuerzas que causan cambios en las frecuencias genéticas (15). En bovinos, el desequilibrio de ligamiento ha permitido explorar el grado de diversidad entre razas y detectar regiones genómicas que han estado sujetas a presiones de selección. La información actual sobre mapas de desequilibrio de ligamiento indica que éste es alto entre marcadores de tipo microsatélite, no solo en loci que se encuentran localizados a cortas distancias, sino también en loci localizados a más de $40 \mathrm{cM}(16)$.

En un estudio realizado por McKay et al (17), se generó un mapa de desequilibrio de ligamiento comparativo entre 8 razas de bovinos para los 29 pares de cromosomas. En este se utilizaron diferentes marcadores, incluyendo polimorfismos de nucleótido único (SNP), encontrando que el desequilibrio de ligamiento para las razas Bos indicus es un poco menor que para las razas de Bos taurus (17). Ello puede deberse a que los marcadores tipo SNPs seleccionados tenían una frecuencia alélica menor, o que el resultado pueda reflejar un tamaño efectivo poblacional mayor dentro de la historia de las poblaciones de ganado Bos indicus. Una interesante conclusión de esta publicación es que para la identificación de nuevos genes y QTLs dentro del genoma bovino, se hace necesaria una mayor cobertura de marcadores (30.000-50.000), ya que si dos SNPs están localizados a una distancia de $100 \mathrm{~kb}$, el coeficiente de correlación entre ellos $\left(r^{2}\right)$ está entre 0.15 y 0.2 y un QTL que se encuentre a una distancia intermedia entre estos dos marcadores, solamente alcanzará un coeficiente de correlación de 0.3 , lo que conllevaría a la necesidad de utilizar un mayor número de loci para realizar análisis de asociación entre estos y así poder localizar características cuantitativas (17).

Secuenciación de Genomas. El obtener la secuencia de todo el genoma de una especie es una tarea ambiciosa que demanda grandes recursos económicos, técnicos y bioinformáticos tanto para el alineamiento, comparación de cDNA, búsqueda de secuencias blanco de expresión (ESTs) como para la anotación del genoma completo. El proyecto genoma bovino utilizó toda la plataforma de conocimiento y tecnología derivadas del 
secuenciamiento del genoma humano, con el fin de obtener la secuencia completa de un prototipo del genoma bovino, además de describir el contenido de GC e identificar genes individuales y secuencias que regulan la recombinación genética. Para cumplir con dichos objetivos se utilizaron diferentes estrategias metodológicas con las cuales se obtuvieron bloques de grandes secuencias del genoma, los cuales fueron ensamblados, para finalmente proponer un borrador del genoma en cuestión. A continuación se presentan dos estrategias metodológicas que fueron utilizadas para la secuenciación del genoma bovino.

Secuenciación jerárquica. Este primer método de secuenciación permite trabajar en grupos a nivel mundial para formar consorcios de identificación de cromosomas particulares sin el riesgo de repetición (18).

Mediante esta estrategia el genoma completo es digerido con enzimas de restricción y los fragmentos de hasta $200 \mathrm{~Kb}$ son insertados en vectores de clonación. En el caso de genomas grandes, estos vectores generalmente son cromosomas artificiales de bacterias (BACs) o cromosomas artificiales de levadura (YACs) que luego son clonados, para obtener genotecas que representen el total del genoma a secuenciar. Estos fragmentos a su vez pueden ser subclonados sucesivamente (18).

Una vez secuenciado cada uno de los segmentos contenidos en los BACs 0 YACs, el ensamblaje de estos fragmentos es posible gracias a secuencias comunes que se sobreponen en los extremos. Los distintos bloques se unen para formar los denominados contigs (18). Sin embargo, es posible que haya interrupciones en el alineamiento de las secuencias (gaps) como resultado de segmentos que no fueron secuenciados o que no fueron clonados, estos se completan utilizando diferentes metodologías. El ensamblaje completo del genoma de las secuencias individuales de los clones de BACs se realiza en tres pasos: filtro, ensamblaje y unión. En el primero, los fragmentos contaminantes son removidos; en el segundo, se genera un ordenamiento de los contigs para cada genoteca de BAC y finalmente la secuencia completa del genoma es obtenida por alineamiento de los extremos superpuestos de los distintos BACs. El resultado es un andamiaje de secuencias de los contigs que constituye la secuencia borrador del genoma (18).

Secuenciación por shotgun. En esta metodología (del perdigonazo por su traducción del inglés) el genoma completo es fragmentado utilizando métodos físicos o enzimáticos, con el fin de obtener múltiples segmentos pequeños de ADN que luego son clonados y secuenciados. Este método a diferencia del jerárquico, implica que los múltiples clones son secuenciados una 0 varias veces y la obtención de secuencias no es de manera consecutiva a lo largo de la longitud del cromosoma (18).

En la metodología de secuenciación por shotgun, una vez obtenida la secuencia, se utilizan algoritmos de computador para ensamblar los contigs derivados de miles de secuencias que se superponen. Los contigs son derivados de genotecas de plásmidos que han sido generados de una genoteca total. Los vectores de clonación son similares a los utilizados en la secuenciación jerárquica (BACs y YACs). Celera, una compañía estadounidense especializada en desarrollo de equipos automatizados de secuenciación ha implementado diferentes tipos de software tales como: Screener, Overlapper, Unitigger, Scaffolde, Repeaty Resolver para ensamblar los distintos contigs (18).

Anotación de genes. Una de las aplicaciones inmediatas de la secuenciación de cualquier genoma reside en la anotación de los genes que lo constituyen. La anotación consiste en la identificación de los genes en el genoma estudiado, para posteriormente determinar su posible función. La anotación se lleva a cabo mediante búsquedas bioinformáticas de regiones universales que caracterizan a todas las secuencias codificantes: marcos abiertos de lectura (ORF)s, cajas TATA, secuencias conservadas en los límites exón-intrón y regiones de alto contenido de CG. Para ello existen varios programas computacionales que permiten la búsqueda 
de estas secuencias sobre los genomas, tales como Gene Finder y Grail, los cuales pueden predecir hasta un $90 \%$ de genes verdaderos. Sin embargo, existen algunas dificultades debido a la complejidad de algunos genes dentro de las especies, tales como localización de genes dentro de intrones de otros genes y regiones no codificantes de alta complejidad. En estos casos se han implementado nuevos programas computacionales como Genie, Genscan, HMMgenes, F genes, que permiten localizar genes a pesar de la complejidad de algunas regiones genómicas (18).

\section{Descripción molecular del genoma bovino}

El genoma bovino está constituido por 29 pares de autosomas y un par de cromosomas sexuales. La mayor diferencia cariológica entre las dos especies de ganado bovino (Bos taurus y Bos indicus) se encuentra en el cromosoma Y: en Bos indicus este cromosoma es acrocéntrico mientras que en Bos taurus es submetacéntrico (19).

Un mapa inicial derivado de clones de BACs del genoma bovino fue construido a partir de fragmentos de restricción de 290.797 clones de animales de tres diferentes razas, que incluyeron Hereford, Holstein y Angus (10), luego fueron incluidos los genotipos y pedigríes de dos mapas genéticos y un set de marcadores obtenidos a partir de mapas de híbridos por radiación, los cuales fueron consolidados en un mapa con 17.254 marcadores en total (10). El primer borrador de la secuencia del genoma bovino fue generado a partir de un individuo de la raza Herford (Li Dominette 01449), mientras que la base de datos para SNPs ha sido generada a partir de seis razas diferentes: Holstein, Angus, Jersey, Limousin Norwegian Red y Brahman (9).

De la información obtenida tanto de los mapas físicos, genéticos y del secuenciamiento, se estima que el total del genoma bovino consta de 2,87 Gpb (2870 millones de pares de bases), a la fecha se ha reportado la anotación de 4000 genes, de los 22,000 que probablemente lo constituyen. Además se han identificado 496 micro RNAs, la mitad de ellos se encuentran distribuidos en 60 grupos génicos separados por $10 \mathrm{~Kb}$, conteniendo de 2 a 7 genes cada uno (9).

El contenido total de GC es de $41,7 \%$, y al igual que en otros mamíferos el genoma está compuesto de muchos elementos transponibles y un número de repeticiones específicas para rumiantes, que constituyen cerca del $27 \%$ del total de genoma (9).

La densidad de genes en bovinos aún no ha sido establecida con precisión, para humanos se ha estimado en 6 genes por $\mathrm{Mb}$. Al parecer en algunas regiones del genoma bovino, la densidad podría estar en 10 genes por $\mathrm{Mb}$, mientras que en otras podría ser de tan solo 2 genes por Mb 10 . En bovinos se observa que el número de genes inferidos por tamaño de los cromosomas difiere considerablemente respecto a la longitud física del mismo. De acuerdo con Mark et al (20) los cromosomas BTA18 y BTA19 tienen más genes que los esperados de acuerdo a su tamaño.

\section{Regiones Dispersas}

Elementos cortos dispersos (SINE). Son secuencias cortas de no más de 400 $\mathrm{pb}$ repetidas hasta en un millón de copias dentro de los genomas (21). En la mayoría de las especies incluyendo las plantas, éstas han sido muy probablemente incorporadas dentro del genoma por retrotransposición de un gen único para RNA 7SL, el cual hace parte de un complejo ribo proteico de señales citoplasmáticas (22). En humanos existen más de 100.000 de estos elementos y un ejemplo típico son las secuencias Alu (21).

En los bovinos puede ser difícil diferenciar entre las secuencias microsatélites, es decir secuencias de ADN de alta repetición en tandas y el ADN repetitivo disperso, debido básicamente a que comparten una serie de elementos comunes (23-25). Un 39\% de la tripleta AGC está asociada con el elemento SINE Bov-A2 (8). Esta alta asociación es una característica importante del genoma 
de los bovinos, si se compara con el genoma de los cerdos en donde solamente existe un porcentaje de asociación entre el 12 y el $24 \%$.

En un estudio realizado por Alexander et al (26), se describe una particular asociación entre la secuencia del elemento repetitivo de artiodáctilos (SINE ARE) y un microsatélite en porcinos y se sugiere una homología compartida con su contraparte en ovinos y bovinos. Esta asociación SINE-microsatélite ha sido utilizada para desarrollar iniciadores específicos y amplificar regiones (de manera similar a los Alu en humanos) del genoma de rumiantes. Otra particularidad del genoma de los rumiantes, cuando se los compara con el genoma de ratón, cerdo o con el mapa humano, es que los microsatélites no forman asociaciones (27). En las especies no rumiantes se observa asociación de microsatélites aparentemente inseparables por recombinación (8).

Elementos largos dispersos (LINE). Los genomas de mamíferos están repletos de secuencias largas dispersas (LINE) de muchas kilo pares de bases de longitud y con dos marcos abiertos de lectura, uno de los cuales codifica para la retrotranscriptasa. En humanos la familia más común es la LINE 1 y consiste de 200.000 a 500.000 copias de casi $6.1 \mathrm{~Kb}$ de longitud (21).

En bovinos existen dos tipos de elementos dispersos largos: Bov A y Bov B, que ocupan entre 1.6 y $1.8 \%$ del genoma total respectivamente. La secuencia Bov A es una región de 115 bp, la cual generalmente puede estar duplicada y se denomina Bov-A2. También puede estar asociada con un pseudogen para un tRNA de Glicina, en cuyo caso se le llama BovtA (8). Otro tipo de repetición considerada inicialmente como SINE corresponde a un elemento de 560 pb (Art-2), el cual se evidencia después de digerir el genoma total con la enzima de restricción PstI. Recientemente se ha descrito mejor y el elemento completo corresponde a una secuencia de $3,1 \mathrm{~Kb}$ asociada con BovB 8 (BovB-Art2), sin embargo como resultado del secuenciamiento del genoma completo se encontró que BovB contiene un marco de lectura abierto, indicando que este elemento puede estar aún activo 8. Puesto que BovA y BovB poseen regiones homólogas en su extremo $5^{\prime}$, ello sugiere el posible papel como regiones promotoras (8) para genes localizados en dirección $3^{\prime}$, en particular aquellos blancos para la actividad de la transcriptasa inversa.

Otras secuencias LINE han sido encontradas en el genoma de bovinos tal como la conocida secuencia Bovino adenosina trifosfato (BATPS) localizada en el segundo intrón del gen para la adenosina trifosfato sintetasa; parte de esta secuencia ha sido reconocida también dentro del pseudogen para la alfa-lacto albúmina (8).

ADN satélite. Este tipo de secuencias de ADN fue primero identificado como bandas satélites respecto a una banda principal, cuando el ADN se ultra centrifugaba en gradientes de densidad (28), ahora el término ADN satélite hace referencia a cualquier secuencia repetida en tándem (29). Este ADN se encuentra localizado principalmente en el centrómero. Existe en el centrómero de los bovinos tres secuencias cortas, que se cree se formaron a partir de la duplicación o triplicación de una corta secuencia única de entre 11 y $12 \mathrm{pb}(8)$.

EI ADN satélite en los bovinos representa a más de un cuarto del contenido total del genoma. La separación de éste por centrifugación en gradientes de densidad permite identificar ocho grandes porciones de ADN satélite (1706, 1709, 1711a, $1711 \mathrm{~b}, 1715,1720 \mathrm{a}, 1720 \mathrm{~b}$ y $1723 \mathrm{~g} /$ cm3) y once componentes menores; representando un 23 y $4 \%$ del total respectivamente. La porción de 1706 fue la primera secuenciada (8) y se observó que está compuesta de una región de 2350 $\mathrm{pb}$ con una estructura de repeticiones alternadas de dos subsecuencias cortas, una de $12 \mathrm{pb}$ y otra de $11 \mathrm{pb}$.

Se ha demostrado $24,26,30$ que las diferentes porciones de ADN satélite bovino comparten secuencias similares. Por ejemplo el componente de 1715 
corresponde a un elemento básico de 31 $\mathrm{pb}$ repetido en tándem para formar una secuencia de $1402 \mathrm{pb}$, que a su vez se repite hasta 110.000 copias en el genoma de bovinos. Dos elementos diferentes han sido descritos en la región 1711 (1711a y $1711 \mathrm{~b})$; el segmento de $1711 \mathrm{~b}$ es idéntico al elemento satélite de 1715 pero con una inserción de 1198 pb, llamado INS$1711 \mathrm{pb}$, cercanamente relacionado con la porción LTR (long terminal repeat) de un retrovirus. La porción 1711a contiene una secuencia llamada INS-1711a de $602 \mathrm{pb}$ la cual comparte un segmento con la secuencia INS-1711b. La porción de 1723 no está relacionada con ninguna de las otras regiones y tampoco contiene unidades de repetición. La unidad de 1709 está compuesta de una secuencia de 3200 pb y aloja las dos secuencias Bov-A2 y Bov-B $(8,30)$.

Microsatélites. Constituyen cortas regiones de ADN, de 1 a 6 pb repetidas en tandas dentro de los genomas eucariotas, cuya repetición puede llegar hasta 60 o más veces (31). Se heredan de forma mendeliana y la posibilidad de tener varios alelos de un locus particular en las poblaciones, los hacen útiles en el análisis de identificación, estudios poblacionales, análisis de enfermedades genéticas particulares asociadas a expansión de repeticiones y genética forense (31-34). Técnicamente los microsatélites son fáciles de identificar utilizando la metodología de Reacción en Cadena de la Polimerasa (PCR), la cual permite flanquear con iniciadores específicos los extremos de los mismos y luego pueden ser detectados con tinción en plata o con fluorocromos en secuenciadores automáticos.

Los microsatélites simples contienen una sola unidad de repetición sin variación en su secuencia, por ejemplo (CAT)n. Los microsatélites compuestos son aquellos con dos o más unidades de repetición con diferente secuencia por ejemplo (CAT) n (TAG)n. Los microsatélites complejos aparecen cuando el microsatélite está compuesto de una serie de unidades de repetición, e interrumpidas por cortas secuencias no repetidas (ej.(TTTC) n
TTाT TTCT (CTTT) n CTCC (TTCC)n. La presencia de microsatélites complejos ha sido reportada en muchas especies, desde humanos (34-36) cabras hasta cerdos (37), sin embargo poco se conoce sobre los mecanismos de evolución de los mismos.

La distribución genómica de los microsatélites es mejor conocida en los humanos y en los ratones, indicando una distribución al azar, con algunas tendencias hacia localización cercana a los telómeros. Particularmente se ha determinado baja frecuencia sobre el cromosoma $X$ humano. La secuencia repetitiva más común en los humanos son los tramos de poly (A)-poly $(T)$, mientras que los di nucleótidos y tri nucleótidos más frecuentes son CA-TG y CAG -AAT respectivamente (31).

En general, en artiodáctilos se ha encontrado un microsatélite de tipo $A C(A)$ $n$ ubicado cerca del gen IGF1 (factor insulinoide de crecimiento tipo 1), cuya función es aumentar la trascripción del mismo, parece ser que la secuencia repetitiva $A C$ forma una estructura $Z$ que aumenta la transcripción (38).

Algunos microsatélites cercanos a regiones promotoras tienen efectos contrarios al aumento de la transcripción o no tienen efecto sobre ella, como se evidencia en el gen del alfa colágeno tipo 2, el cual contiene una secuencia grande repetida cerca de la región promotora, pero sin que ella ejerza ningún efecto sobre la transcripción (31).

En bovinos existen más de 83 microsatélites utilizados para estudios poblacionales, de los cuales aproximadamente 30 son recomendados por la FAO (39) debido a su alta reproducibilidad y polimorfismo. Actualmente los estudios de paternidad en ganado utilizan una batería entre 10 y 15 marcadores de tipo microsatélite recomendados por la Sociedad Internacional de Genética Animal, que incluye los siguientes: TGLA227, BM2113, TGLA53, ETH10, SPS115, TGLA126, TGLA122, INRA023, ETH3, ETH225, BM1824 los cuales han sido seleccionados por presentar un alto contenido de información polimórfica (PIC) y un alto poder de discriminación combinado (40). 
Secuencias codificantes repetidas. LoS genomas eucarióticos también contienen secuencias codificantes repetitivas, tales como los genes para RNA ribosomal (rRNA), de transferencia (tRNA) o familias de genes. En estas últimas, genes ancestrales han dado lugar a genes nuevos por procesos de duplicación génica. Por ejemplo familias génicas encontradas en el genoma de mamíferos, tales como la superfamilia de las globinas o las inmunoglobulinas, han sido generadas por duplicación en tándem seguida de eventos de mutaciones independientes, permitiendo así nuevas funciones (41).

Secuencias únicas. Uno de los primeros genes identificados y mejor conocidos en bovinos en la década pasada corresponde al gen DGAT 1, que codifica la enzima diacilglicerol O-aciltransferasa, fue el primer locus de características cuantitativas (QTL) obtenido mediante clonado posicional en mamíferos (42) y asociado a caracteres de cantidad y calidad de la leche. Cataliza el paso final de la síntesis de triglicéridos y está localizado en el cromosoma bovino (14) (BTA14q). En este gen se ha detectado una sustitución no sinónima en las posiciones nucleotídicas 10433 y 10434 del exón (8), en donde los cambios nucleotídicos de la dupleta AA por GC, causan un cambio de lisina a alanina en la posición 232 de la proteína correspondiente. Este cambio modifica la naturaleza química del amino ácido implicando una disminución en la cantidad de leche, pero un aumento en la cantidad de grasa (42).

Otro gen ampliamente descrito corresponde a la amelogenina (39), proteína importante para la formación del esmalte dental $y$ presente exclusivamente en los cromosomas $\mathrm{X}$ y $\mathrm{Y}$ de humanos y bovinos (43). Existen dos clases de genes para amelogenina, denominados de clase I y de clase II, dependiendo de su localización en los cromosomas $X$ y $Y$, lo que permite la diferenciación molecular entre machos y hembras. Durante la amplificación de estas secuencias de ADN se observan dos bandas bien diferenciadas, una que proviene de la amplificación del gen de clase I (localizado en el cromosoma $X$ ) y la otra del gen de clase II (localizado en el cromosoma Y). La diferencia del tamaño en la amplificación de estos dos tipos de genes es debida a una deleción de $67 \mathrm{pb}$ en el gen de clase II (44) lo que permite la posibilidad de hacer análisis de trazabilidad de carnes por sexo del animal.

Un tercer ejemplo de los genes identificados en bovinos durante la década pasada corresponde al gen que produce la doble musculatura, característica de la raza Azul Belga, pero también presente en las razas Charolais y Senepol. El gen responsable fue identificado gracias al descubrimiento de una mutación que produce un fenotipo análogo en los ratones que se hereda de forma Mendeliana recesiva. En el bovino se encontró que los individuos portadores de la característica tienen una deleción de 11 $\mathrm{pb}$ en el gen de la miostatina (45).

Uno de los eventos epigenéticos más fascinantes en mamíferos es la impronta genética, la cual da como resultado la expresión monoalélica de determinados genes dependiendo del sexo de los individuos. La mayoría de los genes que participan en el mecanismo de impronta en ratón y humano han sido identificados, pero pocos de ellos han sido descritos en ganado (46). El estudio comparativo de genes asociados a impronta genética ha demostrado que de 22 genes comparados, 11 son conservados en humanos y ratones y de los cuales 14 se encontraron que participan en el mecanismo de impronta en bovinos $(47,48)$.

Uno de los ejemplos mejor estudiados respecto al mecanismo de impronta es el que regula la expresión del gen para el factor insulinoide de crecimiento tipo 2 (IGF2), un factor de crecimiento localizado en el locus 11p15 humano y en el cromosoma 7 de ratón. Este gen presenta expresión monoalélica del alelo paterno en la mayoría de los tejidos adultos. La pérdida de la impronta puede ser un factor asociado con cánceres humanos relacionados con el envejecimiento celular incluidos el cáncer de colon y de próstata (49).

Durante el desarrollo el gen IGF2 y el gen H19 se expresan de manera conjunta y 
coordinada sugiriendo que los dos actúan bajo el control de los mismos elementos transcripcionales. Basados en evidencias experimentales desarrolladas en modelos de ratón se postula que existe una región control de la impronta (ICR) localizada entre estos dos genes. Esta región se marca diferencialmente durante la gametogénesis y persiste durante la adultez, determinando la expresión diferencial de los alelos dependiendo de su origen paterno (49).

Cuando la región de impronta cercana al gen $\mathrm{H} 19$ está metilada en el alelo paterno, el gen IGF2 se expresa. La expresión del alelo materno se bloquea cuando la región ICR del gen IGF2 no está metilada. La región flanqueante de la región ICR del gen H19 en ratones, no es muy precisa y abarca una región de 3.8 y $2.0 \mathrm{~Kb}$, una hipermetilación o deleción en este segmento en el alelo materno resulta en la expresión bialélica del gen IGF2. Recientemente se ha encontrado que la reexpresión del alelo materno puede darse debido a que se encontró un motivo de ADN de secuencia CCCTC, al cual se une una proteína de conformación en dedos de zinc conocido como factor CTCF, la cual sólo se une a segmentos de ADN no metilados en la región ICR. Esta unión bloquea el acceso de las proteínas que reconocen y se unen al promotor del gen IGF2, el cual se transcribe desde varios promotores de regulación diferencial. Inversamente, al alelo paterno hipermetilado no se une el factor CTCF y por lo tanto IGF2 es expresado. Se ha demostrado que existen diferencias estructurales y de número en los sitios de unión del factor CTCF lo que podría sugerir diferencias en los mecanismos de regulación por impronta del gen IGF2 dentro de las especies (45).

En general se sabe que en los genes que participan en el mecanismo de impronta existe un alto contenido de CG, además de islas CpG y secuencias repetidas en tandas (43). En general, en dichos genes los elementos SINE son menos frecuentes, mientras que las secuencias LINE se encuentran en mayor cantidad (43).

\section{Reportes del proyecto genoma bovino}

Los resultados recientes obtenidos del primer borrador de la secuencia del genoma bovino (9) revelan que existe una sobre representación de genes involucrados en la reproducción. Estos genes, codifican para una serie de proteínas tales como de señalización intracelular asociadas con la preñez y localizadas en el cromosoma 29, dominios de proteínas del trofoblasto localizadas en el cromosoma 13 y para el interferón Tau cuyo gen se encuentra en el cromosoma 8 (9).

Además se identificaron familias de genes que codifican para proteínas relacionadas con la prolactina (cromosoma 23) y que regulan aspectos tales como el crecimiento fetal, adaptación materna a la preñez y condiciones de parto (9).

El trabajo que reporta los principales hallazgos de la secuencia del genoma bovino completo, menciona evidencias de selección positiva en 71 genes, dentro de los cuales se incluyen 10 genes para la respuesta inmune (IFNAR2, IFN6, CD34, TREM1, TREML1, FCERIA, IL23R, IL24,IL15 y LEAP2) (9), al parecer relacionados con la respuesta a una carga adicional de microorganismos en el rumen, o a la condición de comportamiento grupal de los bovinos, por lo que las enfermedades infecciosas se podrían diseminar más rápidamente. A pesar de que los genes para el interferón están asociados con la defensa inmunológica, el interferón también previene la regresión del cuerpo lúteo durante la preñez, lo que resulta en un ambiente uterino óptimo (9).

Adicionalmente existe una importante reorganización de la familia de genes que codifican para proteínas de la leche. En los bovinos se observa que el gen para la histerina (HSTN) está ubicado físicamente cerca del elemento regulatorio para el gen de la beta caseína (CSN2), lo que hace que estos dos genes se expresen de manera conjunta, sin conocerse hasta la fecha las implicaciones biológicas de esta expresión. Además parece ser que este arreglo causó la deleción del gen CSN1S2A, presente en otros mamíferos (9). 
La comparación de 1.032 genes que participan en diferentes rutas metabólicas en humanos y bovinos, mostró que 5 genes fueron altamente divergentes y exclusivos para bovinos: PLA264C (fosfolipasa), FAAH2 (amino hidrolasa de ácidos grasos), IDI2 (delta isopentil-difosfato),GSTT2 (glutato transferasa), TYMP (timina fosfolipasa), los cuales pueden representar diferentes tipos de adaptaciones al metabolismo de ácidos grasos, la vía de mevalonato (síntesis de dolicoles, vitaminas, hormonas, esteroides y colesterol), desintoxicación y metabolismo de pirimidinas (9).

Ortología de genes. El consorcio del análisis y secuenciación del genoma bovino reporta que hay aproximadamente 14.345 grupos ortólogos presentes en 7 especies de mamíferos estudiadas, de los cuales 1.217 están ausentes o no detectadas en genomas de mamíferos no placentados $(9,50)$.

La comparación bovino-humano, muestra que estos dos grupos son más similares entre sí, que humano-roedor, como se pensaba anteriormente. En general, la mayoría de los cromosomas bovinos contienen secuencias humanas, con o sin re arreglos internos. Cuatro cromosomas bovinos muestran una sintenia completa respecto a sus homólogos humanos: BTA12 (cromosoma 12 de $B$. taurus 12) con HSA13 (cromosoma 13 de $H$. sapiens), BTA19 con HSA17, BTA24 con HSA18, y BTAX con HSAX. Los únicos cromosomas bovinos que no muestran rearreglos internos son los cromosomas BTA9, BTA23 y BTA3. Los cromosomas bovinos BTA23 y BTA9 pudieron haber surgido a partir de una fisión céntrica de un cromosoma ancestral HSA6 del cromosoma humano, HSA6 pudo haber surgido de una fusión céntrica de los cromosomas bovino BTA23 y BTA9 (20).

El análisis de la región cromosómica BTA1q12, demarcada entre los genes KRTAP8P1 (keratine associated protein 8 pseudogene 1 ) y CLIC6 (cloride intracelular channel 6) ha sido de gran interés en la genética bovina debido a que, al parecer allí seencuentran los genes para la característica dominante sin cuernos o fenotipo romo.
Comparaciones con secuencias humanas mostraron 31 genes ortólogos humanos de la región 21q22, de los cuales 16 fueron clonados y mapeados por primera vez en los bovinos. Adicionalmente, este análisis mostró una secuencia de $4 \mathrm{Mb}$ conservada con respecto al orden de los genes para bovinos, humanos y ratones (51).

Secuencias teloméricas: Las secuencias teloméricas se conservan intactas entre los cromosomas humanos y bovinos, en donde más de 15 cromosomas comparten esta homología de secuencia (17). También se ha encontrado que ocho cromosomas bovinos son homólogos a nueve brazos largos de cromosomas humanos (ej. BTA18 es homólogo tanto a HSA16q como a HSA19q), y una región de 0.1-1.7 Mb del cromosoma HSA2p es homóloga al cromosoma BTA8 $(8,48,50-52)$.

Se identificaron 1,020 segmentos de duplicación (SDs) que corresponden a $3.1 \%$ del genoma (94.4 Mb). Se postula que dichas regiones podrían promover arreglos cromosómicos. La duplicación de genes para proteínas que intervienen en la respuesta inmune, receptores sensoriales y olfativos corresponde a un $76 \%$ de estas secuencias duplicadas, las cuales pueden ser generadas por recombinación no homóloga (9).

En conclusión, el avance de las metodologías para secuenciación y obtención de datos genómicos y de anotación de genes ha permitido la intensificación en el desarrollo de software que permiten el análisis rápido de secuencias específicas, así como la producción de nuevas metodologías de secuenciación, con lo cual nuevos proyectos genoma en otras especies podrán terminarse en un menor tiempo y a un menor costo.

El conocimiento de la secuencia completa del genoma de especies económicamente importantes, ha permitido la utilización de herramientas de la biología molecular en la descripción de muchos genes de producción. Derivado de estos análisis se han desarrollado kits comerciales para identificar genes de patologías y rasgos 
productivos con lo cual en el futuro se permitirá la masificación en el diagnóstico y por lo tanto granjas más saludables y productivas.

Con el conocimiento de la secuencia completa del genoma bovino, se obtendrá información de un mayor número de SNPs, importantes para la detección de QTLs. Se estima que este tipo de marcadores se encuentran localizados a distancias aproximadas de $1435 \mathrm{pb}$, lo que implicaría que en el genoma total del bovino estarían presentes cerca de 2 millones de polimorfismos de esta naturaleza, lo que permite afinar el estudio de genes y QTLs, como también el análisis de las fuerzas evolutivas que pueden estar afectando las poblaciones.
Por otra parte, el conocimiento de la homología entre especies permitirá la utilización de ologonucleótidos interespecíficos que posibiliten la descripción de genes en especies evolutivamente cercanas y poco conocidas y los estudios genético poblacionales que permitan evaluar el efecto y magnitud de fuerzas evolutivas que han moldeado la diversidad actual de los bovinos.

Todo este conocimiento permitirá un mayor desarrollo de la proteómica y la fármacogenética lo que implica el entendimiento de la estructura, función y regulación génica en el genoma de los bovinos.

\section{REFERENCIAS}

1. Sanger $F$, Thompson EOP. The amide group of insulin. Biochem J 1955; 59:509-514.

2. Stahmann MA, Hueber $C F$, Link KP. Studies of the hemorrhagic sweet clover disease. V. Identifications and synthesis of the hemorrhagic agent. J Biol Chem 1941;138:513-517.

3. Collip JB. The extraction of parathyroid hormone which will prevent of control parathyroid tetany and which regulates the level of blood calcium. J Biol Chem 1925; 63:395-438.

4. Fevold HL, Hisaw FL, Leonard SL. The gonad stimulating and the luteinizing hormones of the anterior lobe of the hypophesis. Am J Physiol 1931; 97:291-301.

5. Wiltbank JN, Ingalls JE and Rowden WW. Effects of various forms and levels of estrogens alone or in combinations with gonadotrophins on the estrous cycle of beef heifers. J Animal Sci 1961a; 20:341-352.
6. Events $\mathrm{H}$ and Long $\mathrm{JA}$. The effect of the anterior lobe of the hypophysis administered intraperitoneally on growth, maturity and estrous cycles of the rat. Anat Rec 1921; 21:61-63.

7. Foote $\mathrm{RH}$. The history of artificial insemination Selected notes and notables. J Anim Sci 2002;80:1-10.

8. Ruvinsky Fries R. The Genetics of the Cattle. Cataloging in publication Data. United Kingdom. CAB International Library of Congress 1999.

9. The Bovine Genome sequencing and Analysis Consortium, Elsik Christine G, Tellam Ross L, Worley Kim C. The Genome Sequence of Taurine Cattle: A Window to Ruminant Biology and Evolution. Science 2009;324:522-527.

10. Snelling $W$. and 53 authors for the International Bovine BAC Mapping Consortium. A physical map of the genome. Genome Biol 2007; 8:165. 
11. Dekkers JCM. Commercial application of marker-and gene-assisted selection in livestock: Strategies and lessons. Journal of Animal Science 2004; 82:313-328.

12. Cox DR, Burmeister M, Price ER, Kim $\mathrm{S}$, and Myers RM. Radiation hybrid mapping: a somatic cell genetic method for constructing high-resolution maps of mammalian chromosomes. Science $1990 ; 250: 245-250$.

13. Baumann JGJ, Wiegant J, Borst P, Van Duijn P. A new method for fluorescence microscopical localization of specific DNA sequences by in situ hybridization of fluorochrome-labeled RNA. Exp Cell Res 1980: 138:485-490.

14. Levin B. Genes. $8^{a}$ ed. New York: Oxford University Press; 2003.

15. MontgomerySlatkin.Linkagedisequilibrium understanding the evolutionary past and mapping the medical future. Nat Rev Genet 2008; 9:477.

16. Vallejo RL, Li YL, Rogers GW, Ashwell MS. Genetic diversity and background linkage disequilibrium in the North American Holstein cattle population. J Anim Sci 2003; 81(3):617-623.

17. McKay SD, Schanbel R, Murdoch B, Matukumalli L, Aerts J, Caoppieters W, Crews D, Dias Neto E, Gill C, Gao $\mathrm{Ch}$, Mannen $\mathrm{H}$, , Stothard $\mathrm{P}$, Wang Z, Van Tessell C, Williams J, Taylor J and Moores S. Whole genome linkage disequilibrium maps in cattle. BMC Genet 2007; 8:74-87.

18. Gibson G, Muse VS. A primer of Genome Science. (MA): Sinauer Sunderland; 2002.

19. Sánchez $C A$, Bueno M. Introgresión genética de bos indicus (bovidae) en bovinos criollos colombianos de origen bos Taurus. Acta Biológica Colombiana 2008; 13(1):131-142.
20. Mark R Band, Joshua H. Larson, Mark Rebeiz, Cheryl A Green, D Wayne Heyen, Jena Donovan, Ryan Windish, Chad Steining, et al. An Ordered Comparative Map of the Cattle and Human Genomes. Genome Res 2000; 10:1359-1368.

21. Guizar-Vázquez, Jesús. Genética Clínica. Diagnóstico y manejo de las enfermedades hereditarias. México, D.F: Manual Moderno 2001.

22. Feng-Jie Sun, Sophie Fleurdépine, Cécile Bousquet-Antonelli, Gustavo Caetano-Anollés and Jean-Marc Deragon. Common Evolutionary trends for SINE RNA structures. Trends Genet 2007; 23(1):26-33.

23. Pech $M$, Streeck RE, and Zachau HG. Patchwork structure of a bovine satellite DNA. Cell 1979; 18:883-893

24. Silja Kostia. Genomic Evolution and Diversity in Artiodactyla. Academic Dissertation in Genetics, Helsinski: Department of Biosciences, Division of Genetics, University of Helsinki; 2000.

25. Duncan $\mathrm{CH}$. Novel Alu type repeat in Artiodactyls. Nucleic Acids Res 1987; $15: 1340$

26. Alexander LJ, Rohrer GA, Stone RT, and Beattie CW Porcine SINE associated microsatellite markers: evidence for new artiodactyl SINEs. Mamm Genome $1995 ; 6: 464-468$.

27. Pepin LAU, Lepingle $A$, Berthier $J L$, Bensaid $A$, and Vaiman. Sequences conservation of microsatellites between Bos taurus (cattle), Capra hircus (goat) and related species. Examples of use in parentage testing and phylogeny analysis. Heredity $1995 ; 74: 53-61$.

28. Corneo G, Ginelli E, and. Polli E. A satellite DNA isolated from human tissues. J Mol Biol 1967; 23:619-622. 
29. Charlesworth B, Sniegowski P., and Stephan W. The evolutionary dynamics of repetitive DNA in eukaryotes. Nature $1994 ; 371: 215-220$.

30. Jobse C, Buntjer JB ,Haagsma $\mathrm{N}$, Breukelman $\mathrm{HJ}$, Beintema JJ and Lenstra JA. Evolution and recombination of bovine DNA regions. J Mol Evol 1995; 41:277-283.

31. Goldstein D, and Schlötterer Christian. Microsatellites. Evolution and Application New York: Oxford University Press; 1999.

32. Pimentel de Mello L, Tambasco-Talhari D, Lehmann Coutinho AL, De Almeida Regitano LC. Genetic characterization of Aberdeen Angus cattle using molecular markers. Genet Mol Biol 2003; 26(2):133-137.

33. Sanz A, Uffo O, Miranda I, Martínez S. Empleo de los microsatélites para determinar paternidad en bovinos criollos. Revista Salud Animal 2002; 24(3):166-169.

34. Shriver MD, Jin L, Boerwinkle $E$, Deka $\mathrm{R}$, Ferrell RE, and Chakraborty R. A novel measure of genetic distance for highly polymorphic tandas repeat loci. Mol Biol Evol 1995; 12(5):914-920.

35. Teberlet P, Griffin S, GooseensB, et al. Reliable genotyping of samples with very low DNA quantities using PCR. Nucleic Acids Res 1996; 24:3189-3194.

36. Chung M.Y, Ranum PW, Duvick LA, Servandio A, Zoghbi HJ, and Orr HT. Evidence for a mechanism predisposing to intergenerational CAG repeat instability in spinocerebral ataxia type I. Nat Genet 1993; 5:254-258.

37. Larson G, Dobney K, Albarella U, et al. Worldwide phylogeography of Wild Boar reveals multiple centers of pig domestication. Science 2005; 11(307): 1617-1621.
38. Sharoflou Mohammad Reza and Moran Chris. Conservation within Artiodactyls of an AATA interrupt in the IGF I microsatellite for 19-35 Million years. Mol Biol Evol 2000;17:665-669.

39. FAO. Commision on Genetic Resourses for food and agriculture. Working Group on Animal genetics Resources for food and agriculture. Rome: Third Session; 2004.

40. Egito Andréa A, Albuquerque Maria do Socorro, D Almeida Leonardo, Grattapaglia Dario. Microsatellite based genetic diversity and relationships among ten Creole and commercial cattle breeds raised in Brazil. BMC Genet 2007; 8:83.

41. Li WH and Dan G. Fundamentals of molecular evolution. Sunderland: Sinauer Associates, Inc; 1991.

42. Grisart B, Farnir LJRK, Cambisano N, Kim JJ, Kvasz A, Mni M, Simon P, Frére JM, Coppieters W and Georges M. Genetic and functional confirmations of the casualty of the DGAT1 K23A quantitative trait nucleotide in affecting milk yield and composition. Proc Natl Acad Sci USA 2004; 101(8):2398-2403.

43. Sasaki S, and Shimokawa H. The amelogenin gene. Int J Dev Biol 1995; 39:127-133.

44. Vieira Meirelles Flavio. Desenvolvimiento de Marcadores Moleculares para Determinacao da origen sexual e racial de Productos Cárneos [Tese Doutorado]. Pisausunanga, Brasil: Faculdade de Zooctenia e Engeharia de Alimentos; 2005.

45. Grober $L$, Matin LJR, Poncelet $D$, Pirottin D, Brouwers B, Riquet J, Schoberlin A, Dunner S, Menissier F, Massabanda J, Fries R, Hanset R, George M. A deletions in the bovine myostatin gene causes the double- muscled phenotype in cattle. Nat Genet 1997; 17:71-74. 
46. Killian JK, Nolan CM, Wyllie AA, Li T, $\mathrm{Vu} \mathrm{TH}$. Divergent evolution in M6pIGF2R imprinting from the Jurassic to the Quaternary. Hum Mol Genet 2001; 10:1721-1728.

47. Khabit $H$, Zaitoum Ismail and Kim Eui-Soo. Comparative analysis of sequence characteristics of imprinted genes in human, mouse and cattle. Mamm Genome 2007; 18:538-5

48. Hutter B, Helms V, Paulsen M. Tandas repeats in CpG island of imprinting genes. Genomics 2006; 88:323-332.

49. Curchoe $C$, Zhang S, Bin Y, Zhang $X$, Yang L, Feng D, O'Neill M, Tian XC. Promotor-Specific expression of the Imprinted IGF2 gen in cattle (Bos Taurus). Biol Reprod 2005; 73:1275-1281.
50. Everts de Wind A, Kata Srinivas $R$, Band Mark R, Rebeiz Mark, Larkin Denis, Everts Robin E,et al. A 1463 gene Cattle- Human Comparative Map with Anchor Points defined by Human Genome Sequence Coordinates. Genome Res 2004; 14:1424-1437.

51. Drögemüller C, Wöhlke Anne, Leeb Tosso and Disti Tomar. A $4 \mathrm{Mb}$ high resolution BAC contig on bovine chromosome 1q12 and comparative analysis with human chromosome 21q22. Comp Funt Genom 2005; 6:194-203.

52. Aparna P, Thomas Schiex, Stephanie McKay, Brenda Murdodoch, Zhiquan Wang, James E. Womack, Paul Stothard and Stephen S Moore. Highresolution radiation hybrid maps of bovine chromosome 19 and 29: comparison with the bovine genome sequence assembly. BMC Genomics 2007; 8:310-315 